\title{
Rapid and Simultaneous Determination of Tetrafluoroborate, Thiocyanate and Hexafluorophosphate by High-Performance Liquid Chromatography Using a Monolithic Column and Direct Conductivity Detection
}

\author{
Ling YANG, Hong YU, ${ }^{\dagger}$ and Yaqin WANG \\ College of Chemistry and Chemical Engineering, Harbin Normal University, Harbin 150025, China
}

\begin{abstract}
A method was developed for fast and simultaneous determination of tetrafluoroborate $\left(\mathrm{BF}_{4}^{-}\right)$, thiocyanate $\left(\mathrm{SCN}^{-}\right)$and hexafluorophosphate $\left(\mathrm{PF}_{6}^{-}\right)$by high-performance liquid chromatography using a silica-based monolithic column and direct (non-suppressed) conductivity detection. Chromatographic separation was performed on a Chromolith Speed ROD RP-18e column with tetrabutylammonium hydroxide (TBA) + citric acid + acetonitrile as eluent. The effects of the types of eluent, TBA concentration, acetonitrile volume fraction, eluent $\mathrm{pH}$, column temperature and flow rate on the retention of anions were investigated. The optimized chromatographic conditions were selected. Under the optimal conditions, the baseline separation of $\mathrm{BF}_{4}^{-}, \mathrm{SCN}^{-}$and $\mathrm{PF}_{6}^{-}$was achieved without any interference by other anions $\left(\mathrm{F}^{-}, \mathrm{Cl}^{-}, \mathrm{Br}^{-}, \mathrm{I}^{-}, \mathrm{NO}_{3}^{-}\right.$, $\mathrm{ClO}_{3}{ }^{-}$and $\left.\mathrm{SO}_{4}{ }^{2-}\right)$. The detection limit $(\mathrm{S} / \mathrm{N}=3)$ was $0.42,0.46$ and $1.42 \mathrm{mg} \mathrm{L}^{-1}$ for $\mathrm{BF}_{4}^{-}, \mathrm{SCN}^{-}$and $\mathrm{PF}_{6}^{-}$, respectively. The present method was successfully applied to the determination of $\mathrm{BF}_{4}^{-}, \mathrm{SCN}^{-}$and $\mathrm{PF}_{6}^{-}$in ionic liquids.
\end{abstract}

(Received March 24, 2010; Accepted June 1, 2010; Published August 10, 2010)

\section{Introduction}

Tetrafluoroborate, thiocyanate and hexafluorophosphate are important anions which exist in ionic liquids. Chemically, ionic liquids are just room or low temperature molten salts composed by an often small inorganic anion (bromide, chloride, tetrafluoroborate, hexafluorophosphate or thiocyanate) and a bulky dissymmetrical organic cation, such as the dialkyl-imidazolium, alkyl-pyridinium, alkyl-ammonium or tetralkylphosphonium. ${ }^{1,2}$ The materials are liquid state at room temperature or near room temperature. Recently, with the emerging and development of green chemistry, the applications for ionic liquids are very extensive, involving organic synthesis, catalysis and analytical chemistry. ${ }^{1-5}$ As a new type of green solvent, ionic liquids have been considered to promote the development of green chemistry. In the process of preparation and application of ionic liquids, the determination of cations or anions can determine the kind and the purity of ion liquids. With the expected development of industrialized ionic liquids in future, analytical methods applicable to various matrices for product control and environmental monitoring will be very much in demand. Currently, reports on the analysis of anions in ionic liquids mainly adopt the ion chromatographic method. Villagrán et al. ${ }^{6}$ and Hao et al. ${ }^{7}$ achieved the determination of halide anions in ionic liquids by ion chromatography (IC) with suppressed conductivity. Li et al. achieved the determination of $\mathrm{BF}_{4}{ }^{-}$and other impurity anions $\left(\mathrm{F}^{-}, \mathrm{Cl}^{-}\right.$and $\left.\mathrm{Br}^{-}\right)$in ionic liquids by the same method. ${ }^{8}$ The use of suppressed conductivity detection for determination of hexafluorophosphate and other

† To whom correspondence should be addressed.

E-mail: yuhonghsd@yahoo.com.cn trace impurity anions in ionic liquids by IC has also been reported by $\mathrm{Hu}$ et al. ${ }^{9}$ The authors' group used IC with direct conductivity detection to achieve the determination of tetrafluoroborate ${ }^{10}$ and hexafluorophosphate ${ }^{11}$ in ionic liquids.

Tetrafluoroborate, hexafluorophosphate and thiocyanate were also widely used in human production. For example, tetrafluoroborate concentration in the electroplating solution has a great effect on the quality of the plating layer, so the determination of $\mathrm{BF}_{4}^{-}$in electroplating solution and industrial wastewater is necessary. ${ }^{12}$ Hexafluorophosphate is also widely used in the electrolyte solution as an electrolyte for lithium-ion batteries. Its purity has a great effect on the energy, life and safety of the battery. Therefore, it is very important to establish an effective method for its determination. ${ }^{13}$ Thiocyanate exists widely in sewage, industrial wastewater and metabolites of living organisms. $\mathrm{SCN}^{-}$of high concentration in human body fluid will affect the dialysis process of protein and may even result in giddiness or unconsciousness. Moreover, the existence of $\mathrm{SCN}^{-}$in great quantities is also related to endemic goiter in many places. ${ }^{14} \mathrm{SCN}^{-}$is also hazardous to plants, especially crops. One must better control the content of $\mathrm{SCN}^{-}$in chemical fertilizer. So the determination of $\mathrm{BF}_{4}^{-}, \mathrm{SCN}^{-}$and $\mathrm{PF}_{6}^{-}$is of great significance in production, medical treatment, and other areas.

Now, ion-selective electrodes ${ }^{15}$ and ion chromatography, $y^{8,10,16}$ are the main methods for the determination of $\mathrm{BF}_{4}^{-}$. Katagiri et al. studied the total amount of boron, through converting boron to tetrafluoroborate which was determined by IC with suppressed conductivity detection. ${ }^{16}$ There are several methods for determination of $\mathrm{SCN}^{-}$, such as thiocyanate-selective electrode,,${ }^{17,18}$ spectrophotometry, ${ }^{19,20}$ capillary electrophoresis, ${ }^{21}$ ion chromatography, ${ }^{22-24}$ and ion-interaction chromatography. ${ }^{25-27}$ Ion chromatography $y^{9,11,13}$ and high-performance liquid 
chromatography ${ }^{28}$ have been examined for the determination of $\mathrm{PF}_{6}{ }^{-}$. Kazakevich et al. studied the adsorption isotherms of hexafluorophosphate anion on four HPLC columns with different abilities for dispersive surface interactions. ${ }^{28}$ Fast and simultaneous determinations of $\mathrm{BF}_{4}^{-}, \mathrm{SCN}^{-}$and $\mathrm{PF}_{6}^{-}$are not reported before. Thus, the development of simple, fast and sensitive methods is still desirable for the simultaneous determination of $\mathrm{BF}_{4}^{-}, \mathrm{SCN}^{-}$and $\mathrm{PF}_{6}^{-}$.

Simultaneous analysis of anions mainly relies on ion chromatography. Fast analysis would mean increased operating efficiency, lower costs and ultimately larger profits. Therefore, for ion chromatography, it is necessary to significantly reduce the time it takes to perform separations of ions. Monolithic columns have become an important method for achieving fast and high efficient analysis in IC. As a new separation medium, its dominant characteristics are a large ratio of through-pore size to skeleton-size and a high porosity (about $15 \%$ higher than particulate columns). These allow higher flow-rates of eluent due to lower backpressures without much loss of performance. ${ }^{29,30}$ In recent years, the preparation and application of monolithic columns have been developed rapidly in capillary electrochromatography (CEC), HPLC and IC. ${ }^{30-35}$ The main forms of monoliths are organic polymer monoliths and silica-based monoliths. In IC, there are two methods for anion separation using a silica-based monolithic column. One approach is to use it as the column dynamically coated with hydrophobic cationic modifiers such as tetrabutylammonium ion in the eluent (ion-interaction chromatography)..$^{36-39}$ The other approach is the use of monolithic column permanently coated with cationic surfactant such as cetyltrimethylammonium and dilaurylmethylammonium salt (ion-exchange chromatography). ${ }^{40-43}$

In this work, possibilities for fast ion chromatographic separations are further explored and expanded upon. Our approach is to use the Chromolith Speed ROD RP-18e column, a reversed-phase monolithic silica phase, to perform fast and simultaneous determination of $\mathrm{BF}_{4}^{-}, \mathrm{SCN}^{-}$and $\mathrm{PF}_{6}^{-}$by HPLC with direct conductivity detection. Some factors influencing retention of ions are discussed. The optimum chromatographic conditions are selected. A method that employed a silica-based monolithic column to achieve fast and simultaneous determination of $\mathrm{BF}_{4}^{-}, \mathrm{SCN}^{-}$and $\mathrm{PF}_{6}^{-}$by HPLC with direct conductivity detection is established and applied to achieve the analysis of $\mathrm{BF}_{4}^{-}, \mathrm{SCN}^{-}$and $\mathrm{PF}_{6}^{-}$in ionic liquids.

\section{Experimental}

\section{Instrumentation}

All experiments were carried out on an LC-20A ion chromatograph (Shimadzu, Kyoto, Japan), which consisted of a Model LP-20ADsp liquid delivery pump, a conductivity detector Model CDD-10Avp, an autosample injector Model SIL-20A, a Model CTO-20AC column oven and a system controller Model SCL-10Avp. The column and the conductivity detection cell were placed inside the CTO-20AC column oven for temperature control. The exact column temperature was controlled to within $0.1^{\circ} \mathrm{C}$ using the column oven. The chromatographic system control, data acquisition and data analysis were performed using the LC solution Ver. 1.1 workstation (Shimadzu, Japan). A Millipore Milli-Q water purification system (Millipore, Bedford, MA) was used to deionize distilled water, and the deionized water produced was prepared for eluents and sample solutions. A Model DOA-P504-BN pump (IDEX, USA) was used to degas eluents. A Model PHSF-3F pH meter (Shanghai,
China) was used for $\mathrm{pH}$ measurement. A $0.22-\mu \mathrm{m}$ membrane filter (Automatic science, Shanghai, China) was used to filter eluents and sample solutions.

\section{Reagents}

Tetrabutylammonium hydroxide (TBA) as a $25 \%(\mathrm{w} / \mathrm{w})$ solution in water, tetramethylammonium hydroxide (TMA) as a $25 \%(\mathrm{w} / \mathrm{w})$ solution in water and acetonitrile (HPLC grade) were obtained from Tianjin Guangfu Fine Chemical Research Institute (Tianjin, China). Sodium hexafluorophosphate, sodium tetrafluoroborate and potassium thiocyanate used to prepare standard solutions were supplied by J\&K Chemical Ltd. (Beijing, China). Chloride, bromide, fluoride and sulfate were used as their sodium salts, chlorate and iodide were used as their potassium salts. Phthalic acid, citric acid and all of the inorganic salts above were obtained from Shanghai Chemical Reagent Factory (Shanghai, China). Ionic liquids used as the samples were purchased from Shanghai Chengjie Chemical Ltd. (Shanghai, China). All reagents were analytical grade or better.

\section{Solutions}

Eluents were prepared by titrating the desired amount of TBA and acetonitrile with citric acid to a required $\mathrm{pH}$. The eluents were filtered through a $0.22-\mu \mathrm{m}$ filter, and then degassed for $15 \mathrm{~min}$ prior to use.

Standard solutions of inorganic anions were prepared in $18.2 \mathrm{M} \Omega \mathrm{cm}^{-1}$ water. Stock standard solutions of concentration $1000 \mathrm{mg} \mathrm{L}^{-1}$ were prepared monthly. Working standard solutions from each respective stock solution were prepared in $18.2 \mathrm{M} \Omega \mathrm{cm}^{-1}$ water on a daily basis as required. The solutions were filtered using a $0.22-\mu \mathrm{m}$ membrane filter before injection.

\section{Chromatographic conditions}

All separations were performed on a Chromolith Speed ROD $\mathrm{RP}-18 \mathrm{e}$ column which was bonded with $\mathrm{C}_{18}(50 \mathrm{~mm} \times 4.6 \mathrm{~mm}$ i.d., Merk KGaA, Darmstadt, Germany). The optimized mobile phase for the separation consisted of $0.1 \mathrm{mM}$ TBA $+0.05 \mathrm{mM}$ citric acid $+3 \%$ acetonitrile $(\mathrm{pH} 5.5)$. The flow rate was set at $6.0 \mathrm{~mL} \mathrm{~min}{ }^{-1}$. The column temperature was $30^{\circ} \mathrm{C}$. The inject volume was $20 \mu \mathrm{L}$. Direct conductivity detection was employed. The column was flushed with the mobile phase to achieve stable baseline before injection. In order to remove hydrophobic TBA absorbed on the column, one should flush the column using at least $30 \mathrm{~mL}$ water-acetonitrile (95:5, v/v) eluent after analysis. In this way, the column could be recovered as the previous state.

\section{Results and Discussion}

\section{Effect of different acids in eluent on the retention of anions}

In this experiment, eluents composed of $0.25 \mathrm{mM}$ TBA $+5 \%$ acetonitrile were titrated to $\mathrm{pH} 5.5$ with $0.1 \mathrm{M}$ phthalic acid and $0.1 \mathrm{M}$ citric acid, respectively. The effect of different acids in eluent on the retention of $\mathrm{BF}_{4}^{-}, \mathrm{SCN}^{-}$and $\mathrm{PF}_{6}^{-}$was examined. Citric acid is a better eluent than phthalic acid in terms of short retention time and symmetrical chromatographic peaks. In addition, citric acid has advantages of good solubility and low cost. Phthalic acid needs to be heated during the dissolving process, and crystal particle forming after cooling causes some difficulty during storage. So the suitable acid was citric acid.

\section{Effect of different ion-interaction reagents on the retention of anions}

The effects of different ion-interaction reagents on retention of $\mathrm{BF}_{4}^{-}, \mathrm{SCN}^{-}$and $\mathrm{PF}_{6}^{-}$were investigated. The eluents were 


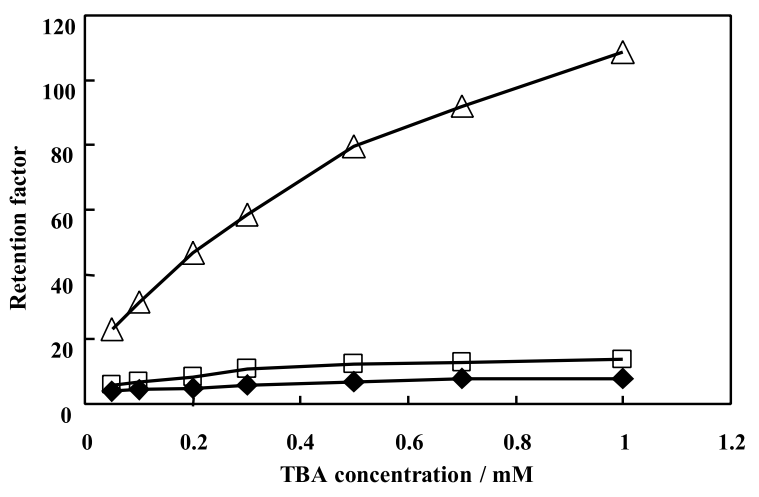

Fig. 1 Relationship curve between retention factor of anions and TBA concentration. Ions $\left(\mathrm{mg} \mathrm{L}^{-1}\right)$ : $\diamond, \mathrm{BF}_{4}^{-}(10) ; \square, \mathrm{SCN}^{-}(10) ; \triangle$ $\mathrm{PF}_{6}{ }^{-}$(15). Column, Chromolith Speed ROD RP-18e column (50 mm $\times$ $4.6 \mathrm{~mm}$ i.d.); eluent, TBA + citric acid $+3 \%$ acetonitrile ( $\mathrm{pH} 5.5)$; flow rate, $3.0 \mathrm{~mL} \mathrm{~min}^{-1}$; column temperature, $30^{\circ} \mathrm{C}$; inject volume, $20 \mu \mathrm{L}$.

prepared with mixture solutions of 5\% acetonitrile and different ion-interaction reagents: $0.25 \mathrm{mM}$ TBA and $0.25 \mathrm{mM}$ TMA, respectively. Then the solutions were titrated to $\mathrm{pH} 5.5$ with $0.1 \mathrm{M}$ citric acid. The results showed that the retention time of all the anions had little difference using TMA as ion-interaction reagent, and the system peak interfered with the determination. A good separation of $\mathrm{BF}_{4}^{-}, \mathrm{SCN}^{-}$and $\mathrm{PF}_{6}^{-}$was obtained using TBA as ion-interaction reagent. Thus, TBA was selected as ion-interaction reagent.

\section{Effect of TBA concentration on the retention factor of anions}

In this study, the eluents with $3 \%$ acetonitrile and different TBA concentrations of $0.05,0.1,0.2,0.3,0.5,0.7$ and $1.0 \mathrm{mM}$ were prepared. Then the solutions were titrated to $\mathrm{pH} 5.5$ with $0.1 \mathrm{M}$ citric acid, resulting in corresponding concentrations of citric acid were $0.02,0.05,0.10,0.20,0.24,0.36$ and $0.46 \mathrm{mM}$, respectively. How the retention factor $(k)$ of anions varied with the TBA concentration was discussed. The relationship between the TBA concentration and the retention factor of anions is shown in Fig. 1. A noticeable increase in retention factor was observed with an increase in TBA concentration. There may be two mechanisms involved in the separation. (1) Some ion-pair reagent (TBA) dynamically adsorbs on the stationary phase to create ion-exchange sites, then the retention takes place by ion-exchange between the anions and adsorbed counter cations (TBA). The adsorption quantity of TBA on the surface of column increases with increasing TBA concentration, leading to larger ion exchange capacity. (2) Some ion-pair reagent (TBA) associates with the anions for forming neutral ion-pairs, and the retention takes place by the hydrophobic interaction between neutral ion-pairs and the stationary phase. The formation ability of a neutral ion-pair enhances with the increasing concentration of ion-pair reagent (TBA), which strengthens the hydrophobic interaction between neutral ion-pairs and stationary phase. In both cases, the retention factors of anions increases especially for the strongly retained $\mathrm{PF}_{6}{ }^{-}$. The separation mechanism is more on the ion-exchange for ions which have strong hydrophilic property, such as $\mathrm{SO}_{4}^{2-}$, while for ions which have strong hydrophobic property, such as $\mathrm{PF}_{6}^{-}, \mathrm{SCN}^{-}$and $\mathrm{BF}_{4}^{-}$, the separation mechanism is more on the hydrophobic interaction. The experimental results showed that the background conductivity values of the eluent increased from 25 to $161 \mu \mathrm{S} / \mathrm{cm}$ with TBA concentration increasing from 0.05 to $1.0 \mathrm{mM}$, and the baseline noise values $(0.010-0.012 \mu \mathrm{S} / \mathrm{cm})$ were basically
Table 1 Linear regression data for plot of $\ln k v s .1 / T\left(\times 10^{3} \mathrm{~K}^{-1}\right)$ of anions ${ }^{45,46}$

\begin{tabular}{lccc}
\hline Analyte & $\begin{array}{c}\text { Slope } \\
(-\Delta H / R)\end{array}$ & $\begin{array}{c}\text { Intercept } \\
(\Delta S / R+\ln \phi)\end{array}$ & $\begin{array}{c}\text { Correlation } \\
\text { coefficient, } r\end{array}$ \\
\hline $\mathrm{BF}_{4}^{-}$ & 0.4906 & -0.1980 & 0.9947 \\
$\mathrm{SCN}^{-}$ & 0.7544 & -0.6567 & 0.9982 \\
$\mathrm{PF}_{6}^{-}$ & 1.0409 & -0.1115 & 0.9987 \\
\hline
\end{tabular}

unchanged. The low background conductivity of eluent would improve the detection sensitivity. The retention factor of anions was lowest with the TBA concentration of $0.05 \mathrm{mM}$, but system peaks interfered with the determination of $\mathrm{PF}_{6}{ }^{-}$. When the concentration of TBA was $0.2,0.3$ and $1.0 \mathrm{mM}$, there was a peak overlapping between system peak and $\mathrm{SCN}^{-}$. An overlay could not be avoided between system peak and $\mathrm{BF}_{4}{ }^{-}$with TBA concentrations of 0.5 and $0.7 \mathrm{mM}$. When the TBA concentration was $0.1 \mathrm{mM}$, the retention factor of anions was relatively less and the background conductivity of eluent was lower with well-shaped peaks. An additional concern was that the system peak would not overlap with any of the analyte peaks. So the proper concentration of TBA was $0.1 \mathrm{mM}$, corresponding to the citric acid concentration of $0.05 \mathrm{mM}$.

\section{Effect of acetonitrile volume fraction in eluent on the retention} factor of anions

Acetonitrile, methanol and isopropanol are used as organic modifiers for ion chromatographic separation. In comparison with other alcohols, acetonitrile is the best choice, because its water mixture has low viscosity, the process of dissolving acetonitrile to water is an endothermic reaction, and moreover, the air bubbles in eluent are relatively fewer. In this experiment, eluents used were $0.1 \mathrm{mM}$ TBA with the acetonitrile volume fraction of 1, 3, 5, 7 and 9\%, then the solutions were titrated to $\mathrm{pH} 5.5$ with $0.1 \mathrm{M}$ citric acid. With acetonitrile volume fraction changing from 1 to $9 \%$, the retention factor of $\mathrm{BF}_{4}^{-}$decreased from 4.8 to 2.6, the retention factor of $\mathrm{SCN}^{-}$decreased from 9.1 to 2.9 , and the retention factor of $\mathrm{PF}_{6}{ }^{-}$decreased from 35.4 to 17.6. The data above showed that the retention factor of anions decreased obviously with the increase of acetonitrile volume fraction. The foregoing discussion indicates that two separating mechanisms exist. With the increase of acetonitrile volume fraction, acetonitrile sweeps off TBA adsorbed on the stationary phase, leading to less ion exchange capacity. Thus, the retention factor of anions decreases, which is in accordance with anion exchange mechanism. Likewise, with increasing concentration of acetonitrile, the surface tension of the eluent is reduced, which in turn reduces solvophobic adsorption of the neutral ion-pair on the stationary phase. Thus, the retention factor of anions decreases, which conforms to a hydrophobic interaction mechanism. The linear regression equations were obtained between retention factor $(\log k)$ and acetonitrile volume fraction $(\mathrm{ACN} \%)$ according to $\log k=c \mathrm{ACN} \%+d:{ }^{44}$ $\log k=-3.65 \mathrm{ACN} \%+0.74(r=0.9934), \log k=-6.45 \mathrm{ACN} \%+$ $1.02(r=0.9970)$ and $\log k=-4.00 \mathrm{ACN} \%+1.60(r=0.9978)$ for $\mathrm{BF}_{4}^{-}, \mathrm{SCN}^{-}$and $\mathrm{PF}_{6}^{-}$, respectively. The results showed that the effect of acetonitrile volume fraction on analyte in the separation was in agreement with that in reversed phase liquid chromatography. When the acetonitrile volume fraction exceeded $5 \%$, the system peak interfered with the determination of $\mathrm{SO}_{4}{ }^{2-}$. Moreover, resolution of $\mathrm{BF}_{4}^{-}$and $\mathrm{SCN}^{-}$was getting markedly worse. To save acetonitrile consumption, the appropriate acetonitrile concentration was $3 \%$. 
Table 2 Effect of flow rate on retention time of anions, column back-pressure and column efficiency

\begin{tabular}{|c|c|c|c|c|c|c|c|c|}
\hline \multirow{2}{*}{$\begin{array}{l}\text { Flow rate/ } \\
\mathrm{mL} \mathrm{min}^{-1}\end{array}$} & \multirow{2}{*}{$\begin{array}{c}\text { Column back-pressure/ } \\
\mathrm{Mpa}\end{array}$} & \multicolumn{3}{|c|}{ Retention time/min } & \multicolumn{3}{|c|}{ Plate height/ $\mu \mathrm{m}$} & \multirow{2}{*}{$\frac{\text { Resolution }}{R\left(\mathrm{BF}_{4}^{-}, \mathrm{SCN}^{-}\right)}$} \\
\hline & & $\mathrm{BF}_{4}^{-}$ & $\mathrm{SCN}^{-}$ & $\mathrm{PF}_{6}^{-}$ & $\mathrm{BF}_{4}^{-}$ & $\mathrm{SCN}^{-}$ & $\mathrm{PF}_{6}^{-}$ & \\
\hline 1.0 & 1.0 & 3.8 & 5.3 & 20.6 & 44.6 & 28.7 & 27.7 & 3.3 \\
\hline 2.0 & 2.0 & 1.9 & 2.7 & 10.4 & 45.1 & 28.8 & 27.9 & 3.1 \\
\hline 3.0 & 3.0 & 1.2 & 1.8 & 6.9 & 45.3 & 29.2 & 28.0 & 3.0 \\
\hline 4.0 & 4.0 & 0.9 & 1.3 & 5.2 & 44.9 & 28.9 & 28.2 & 2.8 \\
\hline 5.0 & 5.1 & 0.7 & 1.0 & 4.1 & 45.4 & 28.6 & 27.8 & 2.7 \\
\hline 6.0 & 6.1 & 0.6 & 0.8 & 3.2 & 45.0 & 28.4 & 27.2 & 2.4 \\
\hline 7.0 & 7.3 & 0.5 & 0.7 & 2.9 & 45.2 & 27.9 & 26.9 & 2.3 \\
\hline
\end{tabular}

Effect of eluent $\mathrm{pH}$ on the retention factor of anions

The suitable $\mathrm{pH}$ range is $2.0-7.5$ for the silica-based monolithic column. Higher pHs will dissolve the silica, creating voids in the column. Lower pHs can eventually strip away some of the bonded phase. All these will cause changes in retention times and loss of resolution. The effect of eluent $\mathrm{pH}$ on retention factor of $\mathrm{BF}_{4}^{-}, \mathrm{SCN}^{-}$and $\mathrm{PF}_{6}^{-}$was investigated. Eluent $\mathrm{pHs}$ were changed through adding $0.1 \mathrm{M}$ citric acid to the solution composed of $0.1 \mathrm{mM}$ TBA $+3 \%$ acetonitrile. With the $\mathrm{pH}$ changed from 5.0 to 7.0, the retention factor of $\mathrm{BF}_{4}^{-}$decreased from 4.8 to 3.6 , the retention factor of $\mathrm{SCN}^{-}$decreased from 7.1 to 5.8 , and the retention factor of $\mathrm{PF}_{6}{ }^{-}$decreased from 31.0 to 26.2. The data above show that the retention factor of anions had no obvious change with the increase of $\mathrm{pH}$; meanwhile, both the background conductivity values of eluent $(24-33 \mu \mathrm{S} / \mathrm{cm})$ and baseline noise values $(0.010-0.012 \mu \mathrm{S} / \mathrm{cm})$ changed slightly, too. At $\mathrm{pH}$ 5.5, each anion had a low retention factor with good baseline, and satisfactory separation was obtained without any interferences by system peak, $\mathrm{F}^{-}, \mathrm{Cl}^{-}, \mathrm{Br}^{-}$, $\mathrm{I}^{-}, \mathrm{NO}_{3}{ }^{-}, \mathrm{ClO}_{3}{ }^{-}$and $\mathrm{SO}_{4}{ }^{2-}$. Eluent $\mathrm{pH} 5.5$ was found to be suitable and so was used in all further work.

\section{Effect of column temperature on the retention time of anions}

In this research, when column temperatures were 25, 30, 35 and $40^{\circ} \mathrm{C}$, the changes of retention time of $\mathrm{BF}_{4}^{-}, \mathrm{SCN}^{-}$and $\mathrm{PF}_{6}^{-}$ are discussed. As the results showed, the retention time of ions decreased slightly with increasing column temperature. The relationship illustrated that the column temperature had little effect on retention of anions. Table 1 lists the linear regression data for plot of $\ln k v s .1 / T\left(\times 10^{3} \mathrm{~K}^{-1}\right)$ of anions at different temperatures. It shows that the linear relation of ions is excellent. The positive slope of the curve illustrated that the retention of anions is an exothermic process (the retention is weakened with the increase of temperature). ${ }^{45,46}$ When column temperature was $30^{\circ} \mathrm{C}$, the retention time of anions was relatively shorter with well-shaped peaks; meanwhile, the baseline was stable. A lower temperature near $30^{\circ} \mathrm{C}$ may result in best column performance. Thus, further study was carried out at $30^{\circ} \mathrm{C}$.

Effect of flow rate on the retention time of anions, column back-pressure and column efficiency

In investigating the effect of flow rate, flow rate was changed from 1.0 to $7.0 \mathrm{~mL} \mathrm{~min}-1$. Table 2 lists the change of retention time, column back-pressure and column efficiency with change of flow rate. The results show that the retention time of anions is obviously shortened with change of flow rate. At the flow rate of $6.0 \mathrm{~mL} \mathrm{~min}^{-1}$, good resolution is obtained within permitted pressure. Column back-pressure is raised with the

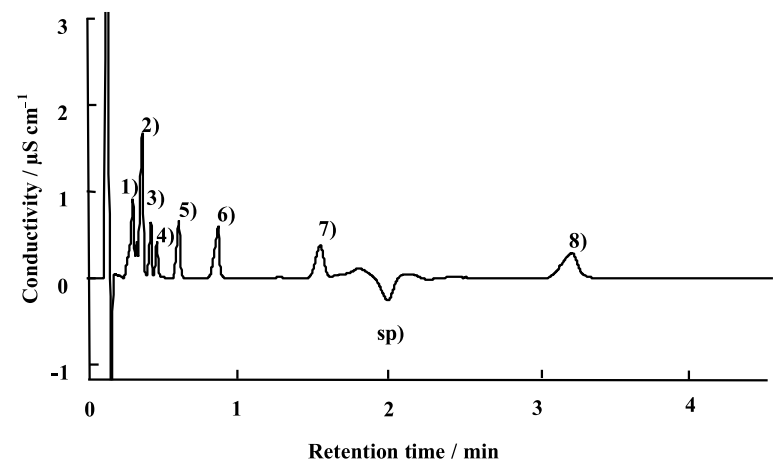

Fig. 2 Separation of a standard mixture of ten anions. Ion $\left(\mathrm{mg} \mathrm{L}^{-1}\right)$ : $1, \mathrm{~F}^{-}, \mathrm{Cl}^{-} ; 2, \mathrm{Br}^{-}, \mathrm{NO}_{3}^{--} ; 3, \mathrm{ClO}_{3}^{--} ; 4, \mathrm{I}^{-}$(the concentration of each anion above is equal as $\left.5.0 \mathrm{mg} \mathrm{L}^{-1}\right) ; 5, \mathrm{BF}_{4}^{-}(10) ; 6, \mathrm{SCN}^{-}(10) ; 7, \mathrm{SO}_{4}{ }^{2-}$ (10); 8, $\mathrm{PF}_{6}^{-}(15)$; sp, system peak. Column, Chromolith Speed ROD RP-18e column $(50 \mathrm{~mm} \times 4.6 \mathrm{~mm}$ i.d. $)$; eluent, $0.1 \mathrm{mM} \mathrm{TBA}+$ $0.05 \mathrm{mM}$ citric acid $+3 \%$ acetonitrile ( $\mathrm{pH} 5.5)$; flow rate, $6.0 \mathrm{~mL} \mathrm{~min}^{-1}$; column temperature, $30^{\circ} \mathrm{C}$; inject volume, $20 \mu \mathrm{L}$.

increase of flow rate, however, at the flow rate of $6.0 \mathrm{~mL} \mathrm{~min}{ }^{-1}$ or even higher, the pressure is still lower than conventional HPLC operating pressure. Column efficiency has just a little change in spite of increase in flow rate. The results show that the monolithic columns employed to achieve the determination of $\mathrm{BF}_{4}^{-}, \mathrm{SCN}^{-}$and $\mathrm{PF}_{6}^{-}$by HPLC have the advantages of high efficiency and rapid completion.

A combination of the above factors gives the optimum chromatographic conditions for the determination of $\mathrm{BF}_{4}^{-}, \mathrm{SCN}^{-}$ and $\mathrm{PF}_{6}{ }^{-}$as $0.1 \mathrm{mM}$ TBA $+0.05 \mathrm{mM}$ citric acid $+3 \%$ acetonitrile ( $\mathrm{pH} 5.5)$ as eluent, column temperature of $30^{\circ} \mathrm{C}$, flow rate of $6.0 \mathrm{~mL} \mathrm{~min}^{-1}$. At the chromatographic condition, the retention times of $\mathrm{BF}_{4}^{-}, \mathrm{SCN}^{-}, \mathrm{SO}_{4}{ }^{2-}$ and $\mathrm{PF}_{6}{ }^{-}$were $0.6,0.8$, 1.5 and $3.2 \mathrm{~min}$, respectively. The mixture of six common anions $\left(\mathrm{F}^{-}, \mathrm{Cl}^{-}, \mathrm{Br}^{-}, \mathrm{I}^{-}, \mathrm{NO}_{3}^{-}\right.$and $\left.\mathrm{ClO}_{3}{ }^{-}\right)$could be separated within $0.5 \mathrm{~min}$. Thus, a good chromatogram was obtained in Fig. 2 without interferences from coexisting ions. In Fig. 2, there is a system peak between $\mathrm{SO}_{4}{ }^{2-}$ and $\mathrm{PF}_{6}{ }^{-}$. The reasons for the source of system peak are complicated and it is very difficult to explain clearly. The system peak may have been caused by the change of conductance of eluent during the elution. After the retained anions were eluted by citrate, the eluent was diluted for a time, which leads to the lower conductance of the eluent, resulting in a negative system peak.

\section{Quantitative parameters}

Detection limit, calibration curve and precision were obtained 
Table 3 Linear regression equation, limits of detection (LOD) and relative standard deviation for anions

\begin{tabular}{lccccc}
\hline Ion & $\begin{array}{c}\text { Linear regression } \\
\text { equation }\end{array}$ & $\begin{array}{c}\text { Correlation } \\
\text { coefficient, } \\
r\end{array}$ & $\begin{array}{c}\mathrm{LOD} / \\
\mathrm{mg} \mathrm{L}-1 \\
(S / N=3)\end{array}$ & $\begin{array}{c}\text { Linear } \\
\text { range/ } \\
\mathrm{mg} \mathrm{L}^{-1}\end{array}$ & $\begin{array}{c}\mathrm{RSD}, \\
(n=5)\end{array}$ \\
\hline $\mathrm{BF}_{4}^{-}$ & $y=118.5 x-15.4$ & 0.9999 & 0.42 & $2-100$ & 1.2 \\
$\mathrm{SCN}^{-}$ & $y=142.9 x+10.8$ & 0.9998 & 0.46 & $2-100$ & 1.0 \\
$\mathrm{PF}_{6}^{-}$ & $y=140.9 x-53.5$ & 0.9999 & 1.42 & $2-100$ & 0.7 \\
\hline
\end{tabular}

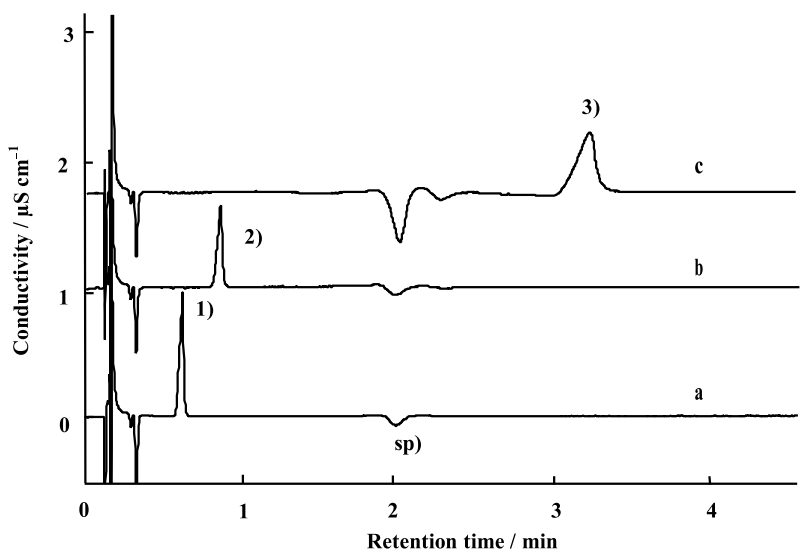

Fig. 3 Chromatograms of ionic liquid samples. (a) 1-Butyl-3methylimidazolium tetrafluoroborate ionic liquid; (b) 1-butyl-3methylimidazolium thiocyanate ionic liquid; (c) 1-butyl-3methylimidazolium hexafluorophosphate ionic liquid. Ion: $1, \mathrm{BF}_{4}^{-}$; $2, \mathrm{SCN}^{-} ; 3, \mathrm{PF}_{6}^{-} ; \mathrm{sp}$, system peak. Chromatographic conditions as in Fig. 2.

by determining a series of standard solutions of $\mathrm{BF}_{4}^{-}, \mathrm{SCN}^{-}$and $\mathrm{PF}_{6}{ }^{-}$under the optimized chromatographic conditions. Data are listed in Table 3. The relative standard deviation (RSD) of chromatographic peak area obtained by repeated measurement $(n=5)$ of a mixture standard sample of $10.0 \mathrm{mg} \mathrm{L}^{-1} \mathrm{BF}_{4}^{-}$, $10.0 \mathrm{mg} \mathrm{L}^{-1} \mathrm{SCN}^{-}$and $15.0 \mathrm{mg} \mathrm{L}^{-1} \mathrm{PF}_{6}^{-}$was less than $1.2 \%$. Calculating with triple signal-to-noise ratio $(S / N=3)$, the detection limits were $0.42,0.46$ and $1.42 \mathrm{mg} \mathrm{L}^{-1}$ for $\mathrm{BF}_{4}^{-}, \mathrm{SCN}^{-}$ and $\mathrm{PF}_{6}^{-}$, respectively. The linear range of calibration curves between peak area and the concentration was from 2 to $100.0 \mathrm{mg} \mathrm{L}^{-1}$ with correlation coefficients $(r)$ of $0.9998-0.9999$ $(n=5)$.

\section{Analysis of sample and recovery experiment}

The proposed method was applied to the determination of three kinds of ionic liquids: namely, 1-butyl-3-methylimidazolium tetrafluoroborate, 1-butyl-3-methylimidazolium thiocyanate and 1-butyl-3-methylimidazolium hexafluorophosphate. The ionic liquids of exactly quantified weights $(0.1-0.2 \mathrm{~g})$ were diluted to $100 \mathrm{~mL}$ as stock solutions. Then the stock solutions of $0.5 \mathrm{~mL}$ were taken out and diluted to $25 \mathrm{~mL}$. The diluents filtered through a $0.22 \mu \mathrm{m}$ membrane filter were used for the determination of $\mathrm{BF}_{4}^{-}, \mathrm{SCN}^{-}$and $\mathrm{PF}_{6}^{-}$with the selected chromatographic conditions. The chromatograms of ionic liquids are shown in Fig. 3. Recoveries were tested by the standard addition method. Analytical results and recoveries are listed in Table 4. Data in Table 4 are the average values of five measurements. The relative standard deviation (RSD) of analytical results is less than $3.0 \%$. Such results indicate that
Table 4 The analytical results and recoveries of anions found in ion liquids

\begin{tabular}{cccccc}
\hline $\begin{array}{c}\text { Ionic } \\
\text { liquid }^{\text {a }}\end{array}$ & $\begin{array}{c}\text { Found/ } \\
\mathrm{mg} \mathrm{L}^{-1}\end{array}$ & $\begin{array}{c}\text { Added/ } \\
\mathrm{mg} \mathrm{L}^{-1}\end{array}$ & $\begin{array}{c}\text { Total } \\
\text { found/ } \\
\mathrm{mg} \mathrm{L}^{-1}\end{array}$ & $\begin{array}{c}\text { Recovery, } \\
\%\end{array}$ & $\begin{array}{c}\text { Content } \\
\text { in ionic } \\
\text { liquid, \% }\end{array}$ \\
\hline 1 & 10.84 & 10.0 & 20.97 & 101.3 & 37.8 \\
2 & 7.45 & 10.0 & 17.46 & 100.1 & 29.3 \\
3 & 14.87 & 10.0 & 25.27 & 104.0 & 36.0 \\
\hline
\end{tabular}

a. 1, 1-Butyl-3-methylimidazolium tetrafluoroborate; 2, 1-butyl-3methylimidazolium thiocyanate; 3, 1-butyl-3-methylimidazolium hexafluorophosphate.

this method has the advantages of high accuracy and good precision, and it has been successfully applied to achieve quantitative analyses of $\mathrm{BF}_{4}^{-}, \mathrm{SCN}^{-}$and $\mathrm{PF}_{6}^{-}$in ionic liquids.

\section{Conclusion}

A method for fast and simultaneous determination of $\mathrm{BF}_{4}^{-}$, $\mathrm{SCN}^{-}$and $\mathrm{PF}_{6}^{-}$by HPLC using a reversed-phase silica-based monolithic column and direct conductivity detection was developed. The experimental phenomenon was discussed according to two retention mechanisms in the separation: ion exchange and hydrophobic interaction. The concentration of TBA and acetonitrile volume fraction in eluent had significant influences on the retention factor of ions. The retention factor of anions increased significantly with increasing the TBA concentration; the retention factor of anions decreased remarkably with the increase of acetonitrile volume fraction. A reversed-phase silica-based monolithic column was applied to achieve fast and low backpressure separation of ions. Compared with suppressed conductivity, direct (non-suppressed) conductivity detection has some merits, such as simple instrument and operation, low cost, and small extra-column band broadening. Detection limits were in the low ppm range, which could meet the requirements of quantitative analysis of ionic liquids. Moreover, this method of high application value can be extended to analysis of other samples of the same kind.

\section{Acknowledgements}

This work was supported by the Natural Science Foundation of Heilongjiang Province (Grant No. B200909) and the Ministry of Education of Heilongjiang Province (Grant No. 11541088).

\section{References}

1. T. L. Greaves and C. J. Drummond, Chem. Rev., 2008, 108, 206.

2. S. A. Shamsi and N. D. Danielson, J. Sep. Sci., 2007, 30, 1729.

3. G. V. Myasoedova, N. P. Molochnikova, O. B. Mokhodoeva, and B. F. Myasoedov, Anal. Sci., 2008, 24, 1351.

4. A. Berthod, M. J. Ruiz-Ángel, and S. Carda-Broch, J. Chromatogr., A, 2008, 1184, 6.

5. T. Charoenraks, M. Tabata, and K. Fujii, Anal. Sci., 2008 , 24, 1239.

6. C. Villagrán, M. Deetlefs, W. R. Pitner, and C. Hardacre, Anal. Chem., 2004, 76, 2118. 
7. F. Hao, P. R. Haddad, and T. Ruther, Chromatographia, 2008, 67, 495.

8. X. H. Li, H. L. Duan, J. T. Pan, and L. F. Wang, Chin. J. Anal. Chem., 2006, 34, S192.

9. Z. Y. Hu, G. W. Pan, and M. L. Ye, Chin. J. Chromatogr., 2009, 27, 337.

10. S. Zhou, H. Yu, and H. J. Ai, Chin. J. Anal. Chem., 2008, $36,1521$.

11. L. Yang, H. Yu, and S. W. Li, J. Instrum. Anal., 2009, 28, 1077.

12. A. N. Araújo, M. B. Etxebarria, J. L. F. C. Lima, M. C. B. S. M. Montenegro, and R. Pérez Olmos, Anal. Chim. Acta, 1994, 293, 35.

13. H. F. Li, J. K. Gao, and S. L. Zhang, Chin. J. Appl. Chem., 2007, 24, 602.

14. S. Olea, L. Ruiz, and P. Justica, J. Anal. Toxicol., 1988, 12, 307.

15. F. Kluger and C. Koeberl, Anal. Chim. Acta, 1985, 175, 127.

16. J. Katagiri, T. Yoshioka, and T. Mizoguchi, Anal. Chim. Acta, 2006, 570, 65.

17. P. H. Yang, W. Z. Wei, and C. Y. Tao, Anal. Chim. Acta, 2007, 585, 331.

18. A. K. Singh, U. P. Singh, S. Mehtab, and V. Aggarwal, Sens. Actuators, B, 2007, 125, 453.

19. J. F. van Staden and A. Botha, Anal. Chim. Acta, 2000, 403, 279.

20. G. Gümü, B. Demirata, and R. Apak, Talanta, 2000, 53, 305.

21. Y. Tanaka, N. Naruishi, H. Fukuya, J. Sakata, K. Saito, and S. Wakida, J. Chromatogr., A, 2004, 1051, 193.

22. S. Chinaka, N. Takayama, Y. Michigami, and K. Ueda, $J$. Chromatogr., B, 1998, 713, 353.

23. J. Cheng, P. Jandik, and N. Avdalovic, Anal. Chim. Acta, 2005, 536, 267.

24. B. C. Blount and L. Valentin-Blasini, Anal. Chim. Acta, 2006, $567,87$.
25. Y. Miura and A. Kawaoi, J. Chromatogr., A, 2000, 884, 81.

26. D. Connolly, L. Barron, and B. Paull, J. Chromatogr., B, 2002, 767, 175.

27. C. R. Harrison, J. A. Sader, and C. A. Lucy, J. Chromatogr., A, 2006, 1113, 123.

28. I. L. Kazakevich and N. H. Snow, J. Chromatogr., A, 2006, $1119,43$.

29. N. Tanaka, H. Kobayashi, K. Nakanishi, H. Minakuchi, and N. Ishizuka, Anal. Chem., 2001, 73, 420A.

30. K. Miyabe and G. Guiochon, J. Sep. Sci., 2004, 27, 853.

31. G. Guiochon, J. Chromatogr., A, 2007, 1168, 101.

32. R. A Wu, L. H. Hu, F. J. Wang, M. L. Ye, and H. F. Zou, J. Chromatogr., A, 2008, 1184, 369.

33. B. Paull and P. N. Nesterenko, Trends Anal. Chem., 2005, 24, 295.

34. D. Schaller, E. F. Hilder, and P. R. Haddad, J. Sep. Sci., 2006, 29, 1705.

35. S. D. Chambers, K. M. Glenn, and C. A. Lucy, J. Sep. Sci., 2007, 30, 1628.

36. P. Hatsis and C. A. Lucy, Analyst, 2002, 127, 451.

37. H. Yu and R. S. Li, Chin. J. Anal. Chem., 2008, 36, 835.

38. S. Zhou, H. Yu, L. Yang, and H. J. Ai, J. Chromatogr., A, 2008, 1206, 200.

39. H. Yu, H. J. Ai, and Q. Chen, Chromatographia, 2009, 70, 1017.

40. P. Hatsis and C. A. Lucy, Anal. Chem., 2003, 75, 995.

41. J. Li, Y. Zhu, and Y. Y. Guo, J. Chromatogr., A, 2006, 1118, 46.

42. K. M. Glenn, C. A. Lucy, and P. R. Haddad, J. Chromatogr., A, 2007, 1155, 8.

43. C. Ó. Ríordáin, L. Barron, E. Nesterenko, P. N. Nesterenko, and B. Paull, J. Chromatogr., A, 2006, 1109, 111.

44. M. J. Ruiz-Angel and A. Berthod, J. Chromatogr., A, 2006, $1113,101$.

45. H. Yu and S. F. Mou, J. Chromatogr., A, 2006, 1118, 118.

46. H. Yu and R. S. Li, Chromatographia, 2008, 68, 611. 